\title{
A Estratégia de Overbooking e sua Aplicação no Mercado de Transporte Aéreo Brasileiro
}

\author{
Overbooking Strategic and it's Application at the Brazilian Air Transportation \\ Market
}

\author{
Renée Baptista Ferraz ${ }^{1}$ \\ Alessandro Vinícius Marques de Oliveira²
}

\begin{abstract}
Resumo
Uma questão fundamental relativa à gestão de empresas aéreas diz respeito ao adequado balanceamento entre oferta e demanda. Grande parte dos vôos das companhias aéreas decola com um número significativo de assentos vazios, sendo uma parcela significativa dessa capacidade ociosa gerada pelos chamados passageiros no-show e pelos cancelamentos de reserva feitos com pouca antecedência em relação ao horário do vôo. No Brasil, o hábito de cancelar a reserva não é comum entre os usuários do transporte aéreo; na maioria das vezes, os passageiros esperam que o prazo da reserva expire ou, quando o bilhete já foi adquirido, simplesmente não comparecem ao embarque. Estas práticas, consentidas pelas empresas aéreas devido à flexibilidade oferecida em determinados bilhetes de passagem (classes tarifárias), inviabilizam a reutilização dos assentos que foram "desocupados” em tempo hábil para o vôo. Desta forma, torna-se economicamente racional que as empresas procurem se proteger das perdas resultantes adotando mecanismos como o aumento virtual da capacidade de uma aeronave, ou overbooking. O presente trabalho tem como objetivo realizar uma análise de eficiência e de riscos com relação à prática de overbooking, ou seja, verificar a viabilidade econômica e os riscos associados de se praticar tal estratégia, apontando suas vantagens e desvantagens, riscos associados e questões referentes às responsabilidades e à legislação.
\end{abstract}

Palavras-chave: overbooking; gerenciamento de receitas; reservas; transporte aéreo.

\begin{abstract}
A key issue regarding airline management is related to the balance between demand and supply. It is a common situation to observe flights departing with a significant amount of empty seats, mainly due to no-show passengers and the very late canceling of reservations. In Brazil, airline passengers do not usually cancel reservations; on the contrary, they usually wait for the deadline to buy it or, if the ticket is already bought, they simply do not show-up. These practices, "allowed" by airlines due the flexibility offer in some fare-classes, impede the airline to sell those empty seats on time for flight departure. Therefore it becomes economically rational for the firms to protect from the losses by recurring to mechanisms such as the virtual increase in flight capacity, that is, overbooking. The present paper aims at developing an analysis of the efficiency of overbooking, discussing its advantages and disadvantages, risks, economic viability, and issues regarding responsibilities and regulation.

Keywords: overbooking; yield management; reservations; air transportation.
\end{abstract}

\footnotetext{
${ }^{1}$ Mestranda do Instituto Tecnológico de Aeronáutica, engenheira civil. E-mail: renee_@terra.com.br

${ }^{2}$ PhD in Economics (Warwick University, UK). E-mail: A.V.MOliveira@gmail.com
} 


\section{Introdução}

A desregulamentação dos mercados de aviação comercial por todo mundo trouxe desafios relevantes às companhias aéreas. Além de se tratar de um setor naturalmente sujeito à instabilidade, tanto de demanda quanto de custos, por ser fortemente atrelado às condições da economia mundial, a situação de maior liberdade aumentou a necessidade de acompanhar a crescente competitividade no mercado, fazendo com que as empresas aéreas visem extrair o máximo da receita possível de cada vôo oferecido.

O presente trabalho tem como objetivo discutir a estratégia de overbooking, apresentando as vantagens e desvantagens de sua aplicação, os riscos associados a tal prática, a viabilidade econômica de sua implantação e as questões referentes às responsabilidades e à legislação. Na seção 2 serão apresentados os conceitos relacionados ao overbooking, como o no-show, regulamentação e procedimentos operacionais. A seção 3 trata da metodologia para a verificação da viabilidade econômica e os riscos associados à prática de overbooking, assim como. Finalmente, na última seção serão apresentadas as conclusões do estudo.

Uma das premissas básicas para a maximização da receita de passageiros é a obtenção do equilíbrio entre a demanda pelo serviço de transporte e a oferta, caracterizada pela capacidade de assentos disponibilizada nos vôos. Para que este equilíbrio seja alcançado, é necessário conhecer características da demanda e da oferta, possibilitando, desta forma, a implantação de sistemas de Revenue Management ou Gerenciamento de Receitas de Ativos Perecíveis GRAP. Estes sistemas têm como objetivo otimizar a produção do serviço de transporte e gerar resultados efetivos, representados por uma maior arrecadação de receitas. Ao contrário das técnicas contemporâneas, fundamentadas nos cortes de custos, reengenharia e downsizing, estas técnicas estão focadas no aumento da receita das empresas.

Os principais elementos que sustentam a implantação de um sistema de gerenciamento de receitas são: a) a diferenciação de produtos, com base na segmentação dos consumidores e na imposição de restrições de reserva, compra e utilização do serviço; b) a discriminação de preços, adotando uma estrutura de preços diferenciados; c) a utilização de técnicas de alocação e controle de estoque de assentos (CEA), ferramenta que permite a determinação dos limites de assentos em cada classe tarifária praticada pela empresa (BOTIMER, 1996) e por fim, d) o overbooking (DAUDEL e VIALLE, 1994), que será analisado nas seções a seguir. 


\section{A Estratégia de Overbooking no Mercado de Transporte Aéreo}

A prática de overbooking tem sido amplamente utilizada por empresas aéreas como uma alternativa para lidar com os problemas de gerenciamento de capacidade nos vôos oferecidos. Esta estratégia implica no aumento virtual da capacidade de uma aeronave, no Sistema de Reservas, com o objetivo de minimizar as perdas de receitas decorrentes dos cancelamentos e no-show de passageiros no momento do embarque. A comercialização de assentos acima da capacidade real de um vôo é fundamentada em questões de custos das empresas aéreas e do próprio comportamento do passageiro: o fato de muitos passageiros efetuarem a reserva e não realizarem a viagem, por quaisquer que sejam os motivos, provoca incertezas às companhias quanto ao aproveitamento de seus vôos, elevando os custos médios e, em última instância, induzindo à racionalidade do estabelecimento de limites de reserva acima da capacidade real disponível.

Em última instância, é a própria política de gerenciamento de receitas (yield management) das companhias aéreas que, visando satisfazer as necessidades dos passageiros que têm alta disposição a pagar por serviços de transporte aéreo, acaba por gerar as questões de no-show e overbooking. Desta forma, o no-show de passageiros é o resultado da "liberdade” ou, como é conhecido no setor de transporte aéreo, da flexibilidade do bilhete de passagem. Em função das diferentes classes tarifárias disponibilizadas em um mesmo vôo, tem-se a comercialização de diferentes “produtos”, representados pelas restrições associadas a cada uma delas.

Praticar o overbooking é uma decisão da empresa aérea. Embora as empresas justifiquem tal prática como sendo uma necessidade para lidar com os problemas de ociosidade gerados pelo no-show de passageiros, é importante lembrar que o no-show é estimulado pelas próprias empresas aéreas, que permitem a remarcação do bilhete ou ressarcimento do valor pago caso o passageiro não compareça ao embarque. Pode-se dizer, então, que o no-show é uma prática estimulada pelas empresas e que, se não houvessem benefícios concretos, tanto com relação à ausência de passageiros (para a empresa aérea, que pode sobrevender assentos e obter maiores lucros) como aos próprios passageiros, em função da comodidade de poder alterar a data da viagem sem perder a validade do bilhete, certamente a prática de no-show não seria permitida e, conseqüentemente, o overbooking não seria necessário.

Assim, pode-se dizer que é a existência do no-show que obriga a existência do overbooking; ou seja, é porque existem passageiros dispostos a pagar pela flexibilidade de seus 
bilhetes, que existe a probabilidade de muitos deles não comparecerem ao embarque. Do ponto de vista da empresa aérea, esta é uma facilidade oferecida aos seus passageiros.

No entanto, devido à impossibilidade de estoque de assentos em uma aeronave (característica de perecibilidade dos serviços de transporte aéreo), se um vôo decolar com capacidade ociosa, a oportunidade de comercializar os assentos não ocupados estará perdida, significando uma perda de receita irrecuperável para a empresa.

A fim de evitar os riscos relativos a estas perdas de receita, as empresas praticam o overbooking como uma forma de controle dos níveis de ociosidade de assentos nas aeronaves. No entanto, esta prática pode resultar em uma situação de risco, em que um passageiro, com reserva confirmada e presente ao embarque no momento do vôo, tenha seu embarque negado devido à falta de assentos disponíveis na aeronave - o chamado denied boarding .

O denied boarding é a materialização do overbooking, e não o próprio, conforme costuma colocar o senso comum. No caso de denied boarding, as empresas devem fornecer ressarcimento ao passageiro cujo embarque foi rejeitado gerando, desta forma, custos à companhia aérea associados ao overbooking. Além disso, podem ser apontados prejuízos reputacionais à empresa, com a geração da desutilidade inerente ao embarque negado - o que certamente acarreta perdas relativas ao posicionamento da firma no mercado.

A ocorrência de rejeições de passageiros ao embarque é conseqüência de um overbooking mal sucedido. As companhias aéreas reconhecem a necessidade desta prática e declaram que através do overbooking controlado podem reduzir o número de assentos vazios e, ao mesmo tempo, atender o interesse dos passageiros, disponibilizando um maior número de reservas nos vôos mais demandados. Realizar o controle do overbooking significa estabelecer o número máximo de assentos a ser comercializado, além da capacidade física do vôo, ou seja, do tamanho da aeronave em termos de assentos, de forma que a empresa não arque com prejuízos, tanto àqueles referentes aos custos de compensação dos passageiros impedidos de embarcar, quanto aos custos associados à receita “desperdiçada” em função dos assentos vazios nas aeronaves e à reputação no mercado.

A escassez de informação quanto às vantagens provenientes do excesso de reservas, das formas de indenização dos passageiros e da tecnologia envolvida nos processos de determinação dos limites de overbooking torna esta prática mal-vista pelos consumidores do transporte aéreo comercial. 
É importante enfatizar, contudo, que o overbooking pode ser benéfico para ambas as partes, ou seja, para as empresas e para o usuário, sendo potencialmente uma estratégia geradora de bem-estar econômico líquido: se, por um lado, as empresas têm a potencialidade de gerar maiores receitas, em virtude do maior número de assentos comercializados e minimização das perdas inerentes à capacidade ociosa nos vôos, também é possível viabilizar maiores opções de viagens àqueles que efetivamente pretendem viajar. A maior disponibilidade aparente de assentos resultará em menos passageiros tendo sua primeira opção de vôo rejeitada, isto é, menos reservas serão recusadas por motivos de excesso de capacidade, permitindo que o passageiro adquira o bilhete para o vôo de sua maior preferência. Além disso, a eficiência na alocação de assentos, representada pela operação de aeronaves com aproveitamento próximo ao limite máximo, permite que o custo por passageiro transportado seja reduzido, podendo ser repassado em forma de descontos às tarifas das passagens aéreas.

O exemplo apresentado a seguir permite uma ilustração do problema associado ao overbooking. Considere uma companhia aérea operadora do mercado constituído pela Ponte Aérea Rio de Janeiro - São Paulo (par-de-aeroportos Congonhas - Santos Dumont). Suponha que a operação é realizada por uma aeronave Boeing B737-300, com capacidade de 132 assentos, e com estatísticas históricas apontando uma média de aproveitamento em torno de 110 a 120 assentos ocupados e 80 no-shows (passageiros que não comparecem ao embarque) em cada vôo, para um determinado dia da semana e horário do dia. Se a empresa aérea aceitar somente 132 reservas, valor equivalente à capacidade real do vôo, a média de aproveitamento será de apenas 52 assentos ocupados no respectivo vôo. Conseqüentemente, de 53 a 63 passageiros serão impossibilitados de efetuar reservas, tendo suas viagens inviabilizadas no vôo em questão. Isso representa em média 44\% de passageiros deixando de gerar receita.

\subsection{No-Show}

Para que se compreendam as razões que levam à racionalidade econômica da prática de overbooking pelas companhias aéreas (e algumas empresas prestadoras de serviço), é preciso, inicialmente, entender o conceito do passageiro no-show, principal responsável pela ociosidade da aeronave (assentos vazios) quando as reservas já foram confirmadas.

Um passageiro no-show é aquele que não comparece ao embarque mesmo após ter confirmado sua reserva, inviabilizando a confirmação de outros passageiros. O no-show pode ser resultado de três fatores causais: intencionais, inevitáveis e por negligência 
(RUPPENTHAL e TOH, 1983). O no-show intencional resulta de passageiros viajando a turismo, que alteram seus planos em última instância, decidindo prolongar sua estadia para aproveitar mais a viagem. Executivos e passageiros a negócios, que adquirem bilhetes sem ou com poucas restrições, também podem estar classificados nesta categoria. Também são considerados intencionais aqueles que efetuam múltiplas reservas, em diversos vôos e de diferentes companhias, a fim de "garantir" a viagem. Nestes casos, este passageiro fatalmente será um no-show nos vôos em que efetuou a reserva e não a cancelou. Já o no-show inevitável resulta de uma categoria de passageiros que deixam de comparecer ao embarque por razões que fogem de seu controle, como por exemplo, aqueles pertencentes a conexões subseqüentes e cujo vôo anterior não chega ao aeroporto no horário previsto. Por fim, o no-show por negligência pode derivar de erros humanos, causados pela negligência de funcionários das empresas aéreas. Erros na identificação do passageiro podem duplicar uma reserva e, conseqüentemente, uma delas resultará em um no-show.

As agências de viagens também são responsáveis pelos índices de no-show verificados nas estatísticas das companhias aéreas. Com o intuito de satisfazer seus clientes, os agentes realizam múltiplas reservas para um mesmo passageiro, que poderá optar pelo vôo que lhe melhor convier, sem a preocupação de cancelar a reserva naqueles preteridos. Mayo (1999) atribui parte do problema a práticas irresponsáveis de agentes e operadores, que bloqueiam certa quantidade de assentos como forma de garantir vendas posteriores, sem o devido controle das empresas.

A aplicação de restrições associadas às diferentes classes de reservas atua como fator limitante ao problema do no-show. Algumas tarifas promocionais exigem que o passageiro compareça ao embarque no horário estipulado, caso contrário estará sujeito a perder o bilhete de passagem, isto é, perder o direito de remarcação ou reembolso do valor pago. A impossibilidade de recuperar o direito de viagem, ou de ser ressarcido, inibe a prática de noshow intencional por passageiros portadores de bilhetes com desconto.

Atualmente, muito se fala na aplicação de multas e penalidades aos passageiros no-show a fim de reduzir tal comportamento. No entanto, a penalização destes passageiros perde o sentido se for considerado que ele paga pelo "direito” de não comparecer ao vôo e re-utilizar o bilhete no momento em que compra um bilhete de tarifa mais elevada. 
Vale ressaltar aqui que a prática de no-show é consentida pela empresa aérea uma vez que esta permite que o passageiro re-utilize seu bilhete de passagem caso não compareça ao embarque do vôo em questão. Se esta flexibilidade do bilhete não fosse oferecida, os passageiros no-show não gerariam prejuízos para as empresas pois o custo do assento ocioso estaria pago, assim como ocorre no transporte rodoviário.

\subsection{Responsabilidades e Regulamentação do Overbooking na Legislação Brasileira}

A prática da estratégia de overbooking é uma questão bastante discutida em âmbito mundial. É um tema polêmico e um tanto contraditório. Uma das questões normalmente levantadas com relação é este tema se refere a quem responsabilizar pela ocorrência de denied boarding nos vôos em isto que se configura. Pode-se dizer que o principal responsável pelo no-show é o passageiro full-fare, cujo bilhete desta classe tarifária apresenta poucas ou nenhuma restrição.

Em face à política de maximização de receitas, as empresas buscam proteger o consumidor que lhe produz maior lucratividade, ou seja, o passageiro que adquire bilhetes nas maiores tarifas disponibilizadas pela empresa. Assim, o passageiro que arca com a conseqüência do overbooking é aquele que não possui o direito de ser um no-show (i.e., passageiros de classes tarifárias do tipo low-fare), em virtude das restrições associadas às tarifas com desconto. Esta condição gera desconforto aos passageiros desta classe de reserva, visto que se consideram injustiçados por serem penalizados por atos cuja responsabilidade não lhes diz respeito. Todavia, pode-se argumentar que os passageiros full-fare, por despender maior quantia pelo bilhete, almejando, entre outros fatores, maior flexibilidade atribuída à viagem, obtêm o “direito” de no-show, enquanto que, em função dos descontos oferecidos nas tarifas promocionais, subentende-se que os passageiros que adquirem estes bilhetes serão, inevitavelmente, potenciais denied boarding em casos de overbooking mal planejado. Esta característica representa aos consumidores mais sensíveis ao preço uma incongruência, fazendo com que se sintam prejudicados e desaprovem a prática de overbooking.

A solução para problemas desta natureza passa pela informação clara e precisa das regras e procedimentos adotados pelas firmas em casos de excesso de passageiros. No entanto, apesar do overbooking ser uma estratégia competitiva largamente utilizada por companhias aéreas em todo o mundo, em que tanto a empresa quanto os passageiros podem ser beneficiários, no Brasil ela é pouco conhecida e, principalmente, pouco esclarecida aos usuários do transporte aéreo. 
A regulamentação acerca deste tema, que envolve empresas aéreas, consumidores e órgãos competentes, se faz necessária com o intuito de minorar os efeitos negativos resultantes desta prática. Assim, leis, estabelecidas com o intuito de amparar os direitos do consumidor, definem critérios para a indenização dos passageiros prejudicados pelo overbooking. A legislação vigente sugere a adoção de políticas de estímulo ao denied boarding voluntário por parte das empresas aéreas, medida esta que visa reduzir os transtornos resultantes de um embarque forçoso, instigando soluções rápidas e justas, através de acordos entre empresa e passageiro.

O contrato de transporte aéreo é definido como um acordo firmado entre consumidor e transportador, onde se convenciona a condução do deslocamento ao destino pretendido do primeiro, através dos serviços prestados pelo transportador, mediante preço e condições previamente estabelecidos. Diante disso, as empresas aéreas tornam-se responsáveis pela realização do transporte de passageiros, sob pena por violação do contrato, consignada através da regulamentação vigente.

Ao regular as obrigações do contrato de transporte, o Código Brasileiro de Aeronáutica (CBAer) prevê o reembolso da importância paga pelo bilhete no caso de cancelamento da viagem por parte do operador, e outras penalidades na ocorrência de atrasos de partida ou interrupção da viagem por um período superior a quatro horas. Entretanto, o CBAer não estabelece tratamento expresso das situações derivadas do overbooking e no-show de passageiros, não penalizando nem acolhendo estas práticas.

Discussões entre membros dos vários setores relacionados ao transporte aéreo demonstram incertezas quanto à regulamentação referente ao não-cumprimento do contrato de transporte. De acordo com o Código Brasileiro de Aeronáutica, em seu artigo 233 e respectivos parágrafos, a execução do contrato de transporte aéreo inicia-se quando o passageiro, já despachado no aeroporto, transpõe a linha que delimita a área pública e entra na respectiva aeronave, ou seja, já superada a fase da possível rejeição ao embarque. Esta menção sugere que os passageiros denied boarding teriam seus direitos salvaguardados não pelo CBAer, mas pelo Código de Defesa do Consumidor (Lei nº 8078/90) e Código Civil Brasileiro, uma vez que o contrato de transporte não estaria concretizado.

Entretanto, existem situações em que a empresa aérea informa a ocorrência deste procedimento aos passageiros somente quando estes já estão estabelecidos a bordo da 
aeronave, solicitando ou impondo que se retirem e aguardem um próximo vôo. Neste caso, o overbooking é constatado dentro do período de cumprimento do contrato aéreo. Algumas posições defendem que apenas perante esta condição é que os passageiros estariam amparados por imposições regulamentares do Departamento de Aviação Civil (DAC).

Em função das divergências e contradições averiguadas, especialistas em direito aeronáutico atribuem as responsabilidades pela não realização do serviço de transporte, objeto de contrato entre transportador e transportado, sujeitas às normas conjuntas de ambos os códigos supracitados ${ }^{3}$.

A fim de facilitar os trâmites relativos aos danos causados pela preterição por excesso de passageiros, foi firmado um Termo de Compromisso entre órgãos representando os interesses do consumidor ${ }^{4}$ e das empresas aéreas ${ }^{5}$. Embora a validade do termo tenha expirado em dezembro de 2001, algumas empresas brasileiras continuam adotando tais políticas em suas bases domésticas ${ }^{6}$. Em relação à ocorrência de acessos negados devido à prática de overbooking em vôos internacionais, um termo de compromisso semelhante foi celebrado com doze empresas estrangeiras que operam no território brasileiro, sob as mesmas condições impostas aos vôos nacionais (Termo de Compromisso de Ajustamento $n^{\circ}$ 55/2002 de 07/11/2002, da Promotoria de Justiça do Consumidor do Ministério Público do Estado de São Paulo).

Segundo a legislação vigente, quando o transportador cancelar o vôo ou este sofrer atraso ou, ainda, houver preterição por excesso de passageiros, a empresa aérea deverá acomodar os passageiros portadores de bilhete de passagem em outro vôo, próprio ou de congênere, que ofereça um serviço equivalente para o mesmo destino, no prazo máximo de quatro horas do horário estabelecido no bilhete de passagem. Caso este prazo não possa ser cumprido, o usuário poderá optar entre viajar em outro vôo (por endosso) ou reembolso do bilhete de passagem.

\footnotetext{
${ }^{3}$ Fonte: Núcleo de Estudos de Direito Aeronáutico (NEDA)

${ }^{4}$ Departamento de Proteção e Defesa do Consumidor (DPDC), Secretaria de Direito Econômico (SDE Ministério da Justiça), Departamento de Aviação Civil (DAC - Comando da Aeronáutica, Ministério da Defesa), Instituto Brasileiro de Defesa do Consumidor (IDEC), Fundação de Proteção e Defesa do Consumidor do Estado de São Paulo (PROCON), Instituto Brasileiro de Política e Direito do Consumidor (BRASILCON).

${ }^{5}$ Sindicato Nacional das Empresas Aeroviárias (SNEA) e as transportadoras aéreas filiadas, e a Junta de Representantes das Companhias Aéreas Internacionais do Brasil (JURCAIB).

6 Fonte: Varig.
} 
Concordando em viajar em outro vôo que não o originalmente reservado, além das compensações (Denied Boarding Compensation - DBC), a empresa aérea deverá proporcionar ao passageiro as facilidades de comunicação, alimentação, hospedagem e transporte de e para o aeroporto, se for o caso. A especificação das alternativas de vôos aos passageiros (horários, escalas, conexões, etc.) também é obrigação da transportadora.

De acordo com o Termo de Compromisso, a compensação dos passageiros rejeitados poderá ser feita por uma das seguintes formas ${ }^{7}$ :

o Crédito compensatório de, no mínimo e sem limite máximo, $105 \mathrm{DES}^{8}$ para trechos até $1.100 \mathrm{~km}$ e 175 DES para trechos superiores a $1.100 \mathrm{~km}$, sob a forma de Miscellaneous Charges Order (MCO), com validade de um ano a partir da data de emissão, podendo ser convertido, a critério do passageiro: a) em dinheiro; b) na aquisição de outro bilhete de passagem aérea, a ser utilizado pelo passageiro; c) em upgrade para classe superior àquela para a qual o passageiro tiver bilhete de passagem, em outro vôo; d) no pagamento de excesso de bagagem;

o Upgrade de classe de serviços;

o Bilhete de passagem aérea adicional;

o Mediante outros acordos definidos entre o passageiro e o transportador.

Ao aceitar a compensação e a inclusão em vôo posterior, o passageiro não perde os direitos estabelecidos no ordenamento jurídico internacional e na legislação brasileira ${ }^{9}$. Entretanto, por aceitar a oferta de compensação da empresa aérea, esta poderá exigir a respectiva quitação, por instrumento que designará o valor pago, a data e o local do pagamento, assinado pelo passageiro, importando para a empresa a exoneração de qualquer outra responsabilidade perante o passageiro, que nada mais poderá reclamar, relativamente aos danos causados pelo overbooking. Cabe ressaltar que a aceitação pela substituição do vôo e os respectivos

\footnotetext{
7 É imprescindível que a reserva tenha sido confirmada e que o passageiro se apresentado ao embarque no horário determinado pela empresa aérea para que possa fazer valer seus direitos em casos de preterição. Segundo a regulamentação, o prazo de comparecimento ao check-in é de, no mínimo, uma hora de antecedência para vôos internacionais e, no mínimo, meia-hora antes do horário previsto para os vôos nacionais, ou de acordo com o estabelecido pela empresa.

8 O valor da unidade monetária mencionada, Direito Especial de Saque (DES), é calculada de acordo com o método de avaliação do Fundo Monetário Internacional em vigor na data em questão, aplicado a suas operações e transações. 1 DES = 1,43754 US dólar (cotação em 04/11/2005), ou aproximadamente 3,19465 Reais; Fonte: Banco Central do Brasil (www.bacen.gov.br).

${ }^{9}$ Fonte: Manual do Usuário do Transporte Aéreo - Capítulo II.
} 
ressarcimentos é facultativo ao passageiro, podendo exigir seu embarque no vôo original. Neste caso, terão prioridade de embarque os menores de 18 anos desacompanhados, gestantes, maiores de 65 anos, portadores de deficiência, membros da mesma família que estiverem juntos, passageiros em trânsito (conexão) e passageiros deportados.

Não havendo acordo entre as partes, o passageiro poderá efetuar reclamação oficial ao DAC, abrindo um processo administrativo que poderá resultar em sanção à companhia por infração ao Código Brasileiro de Aeronáutica.

\subsection{Procedimentos Operacionais Quanto ao Overbooking}

\subsubsection{Empresas Aéreas}

Os procedimentos de escolha de passageiros que terão o embarque negado em virtude da prática de overbooking por empresas aéreas brasileiras baseiam-se, normalmente, na ordem de chegada dos passageiros ao balcão de check-in (algoritmo do first come - first served). Os passageiros são atendidos e aceitos no vôo até que a capacidade disponível seja atingida. No momento em a empresa percebe que o denied boarding está prestes a se concretizar, os funcionários da linha de frente do check-in realizam uma "entrevista” com os passageiros remanescentes (aguardando para atendimento no balcão) em busca de possíveis voluntários que aceitem trocar de vôo e prorrogar a viagem por um período determinado pela empresa. As entrevistas visam estimular a rejeição voluntária, porém, caso não existam passageiros dispostos a tal rejeição, ou a quantidade de voluntários seja insuficiente, a empresa obriga-se a rejeitar passageiros de forma involuntária.

As empresas aéreas, com o intuito de otimizar o aproveitamento econômico da aeronave, costumam priorizar o embarque de passageiros portadores de bilhetes emitidos com tarifas cheias (full-fare), enquanto os portadores de bilhetes de tarifas promocionais não possuem garantia de embarque, em vôos sobrevendidos, até que sejam efetivamente aceitos pelo processo de check-in.

Uma outra forma de selecionar os potenciais denied boardings é feita através de um tratamento diferenciado em função das classes de reservas. As empresas disponibilizam balcões preferenciais para a realização do check-in dos passageiros de classes executiva, primeira classe, portadores de bilhetes full-fare e clientes assíduos (frequent-flyers), privilegiando e priorizando o embarque destes passageiros. 
Adicionalmente, existe a alternativa, já praticada por empresas norte-americanas, da operação de aeronaves com cabines flexíveis, que possibilitam a alteração da configuração interior, facilitando os procedimentos de acomodação dos passageiros em situações de overbooking mal planejado. A disposição das cortinas de separação entre classes pode ser alterada, de acordo com a necessidade de aumentar ou reduzir o número de assentos em cada uma delas.

\subsubsection{Passageiros}

O Departamento de Aviação Civil elaborou um Guia do Passageiro, com informações referentes aos direitos e deveres do consumidor do serviço de transporte aéreo. Nele, além dos procedimentos a serem executados em casos de atraso e cancelamento de vôos, extravio de bagagem, dentre outros, encontram-se os procedimentos pertinentes às situações em que o número de passageiros que se apresentam ao embarque é superior à capacidade do vôo, ou seja, na ocorrência de denied boarding.

De acordo com este documento, os principais procedimentos a serem realizados pelos passageiros preteridos a um vôo são:

o Procurar o supervisor da companhia aérea cujo bilhete foi adquirido e relatar o problema, a fim de verificar as condições de re-acomodação em outro vôo, bem como a negociação das devidas compensações, no caso de acordos amigáveis;

o Se o passageiro optar pelo reembolso da passagem, é necessário verificar a forma como foi feito o pagamento do bilhete, pois os prazos e condições para a devolução do valor pago dependem de tal.

o Na eventualidade da companhia aérea não arcar com suas responsabilidades, o passageiro poderá efetuar reclamação junto ao DAC, sendo esta posteriormente encaminhada ao Presidente da mesma, através de documento oficial.

o Caso o passageiro opte por não realizar acordo com a empresa, não aceitando as facilidades oferecidas por ela, o mesmo deverá, também, efetuar reclamação oficial junto ao DAC, onde será analisada e, se necessário, adotadas sanções previstas no Código Brasileiro de Aeronáutica (CBAer). 
Estatísticas publicadas pelo Departamento de Aviação Civil (DAC) divulgam índices de reclamação registrados, relativos à preterição decorrente do overbooking nas empresas regulares do mercado de transporte aéreo brasileiro (Figura 1).

O gráfico apresenta valores comparativos, do número de reclamações referentes ao overbooking por empresa aérea. Vale ressaltar que o número de reclamações não representa o número de ocorrências.

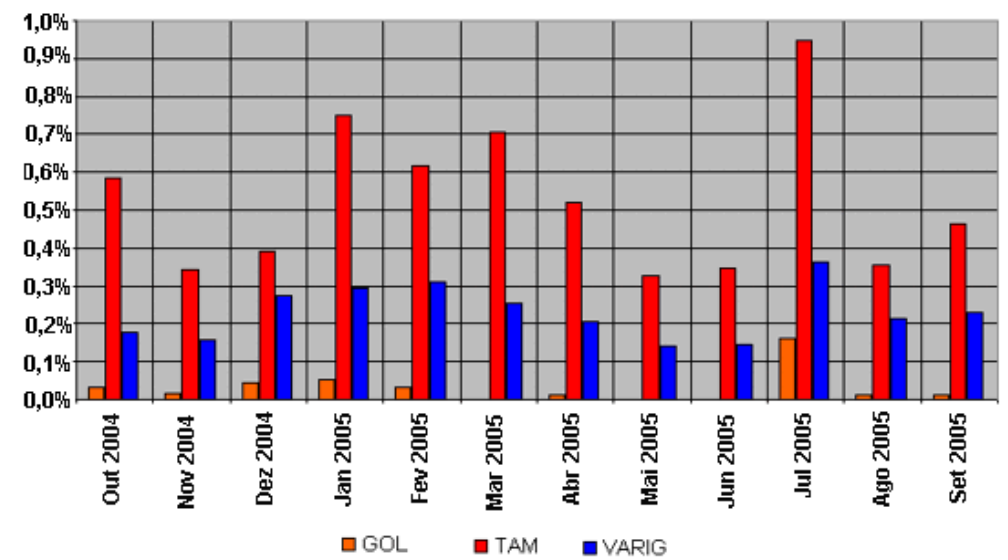

Figura 1 - Estatística de Reclamação de Passageiros Preteridos (Overbooking) - Número de Fonte: DAC. Passageiros Transportados $\times$ Reclamações de Passageiros.

\section{Metodologia: Uma Análise de Viabilidade Econômica na Implantação do Overbooking}

A ocorrência de denied boardings gera custos monetários e reputacionais às empresas. Portanto, as empresas devem avaliar os impactos da estratégia de overbooking, a fim de adequadamente mensurar os retornos e riscos a que estará submetida, comparando cenários alternativos que incluem ou não a sua implantação. Tarefa associada a esta, e igualmente não trivial, diz respeito ao estabelecimento dos níveis de overbooking a serem praticados, caso a tomada de decisão seja a de implantar esta estratégia.

Esta seção tem como objetivo implementar a metodologia do estudo, cuja análise de viabilidade financeira e riscos associados às condições de capacidade serão os tópicos avaliados. 


\subsection{Análise de Riscos: Spoilage $x$ Denied Access}

Os riscos operacionais decorrentes do controle da demanda apresentam impactos diretos nas receitas dos vôos de uma empresa. O processo de overbooking busca o equilíbrio entre o risco de spoilage - capacidade ociosa devido ao baixo número de passageiros no vôo - e o risco de denied access, ou seja, o risco de ter que recusar passageiros em função da alta demanda e baixa oferta. Enquanto o custo associado ao primeiro é a perda de receita em relação à reserva desperdiçada, ou seja, assentos que deixaram de ser comercializados, os custos relativos ao denied access envolvem custos diretos e indiretos (DAUDEL e VIALLE, 1994). Os custos diretos são aqueles despendidos nas compensações dos passageiros cujo embarque lhes foi negado, enquanto que os custos indiretos, estão associados à imagem da empresa perante estes consumidores rejeitados. A condição ideal é aquela em que o número de no-shows é igual ao número de show-ups (os passageiros que comparecem ao embarque no momento do vôo).

Duas são as maneiras de interpretar os reflexos da prática de overbooking planejado (DAUDEL e VIALLE, 1994). A primeira é que com o aumento da porcentagem de overbooking obtém-se uma diminuição do risco de spoilage, porém obtém-se um aumento do risco de denied access, em que passageiros com reservas confirmadas serão impedidos de embarcar. A segunda maneira de interpretação é a da substituição, por parte da empresa, do conceito de spoilage pelo conceito de receita gerada pela sobrecapacidade reservada, ou seja, pela prática de overbooking.

Considerando a receita de overbooking $\left(\mathrm{R}_{\mathrm{ovb}}\right)$ como dada por

$$
\mathrm{R}_{\mathrm{ovb}}=\mathrm{R}_{\mathrm{Md}}-\mathrm{C}_{\mathrm{DA}}
$$

onde $\mathrm{R}_{\mathrm{Md}}$ representa a receita média gerada por assento reservado e $\mathrm{C}_{\mathrm{DA}}$ o custo associado ao acesso negado, ou seja, os custos de compensações e indenizações aos passageiros impedidos de embarcar. Neste caso, verifica-se que aumentando o nível de overbooking, a receita cresce até atingir um ponto ótimo, onde o custo marginal de se rejeitar um passageiro é igual à receita média gerada por um passageiro adicional, sofrendo decréscimo a partir deste ponto (Figura 2). 


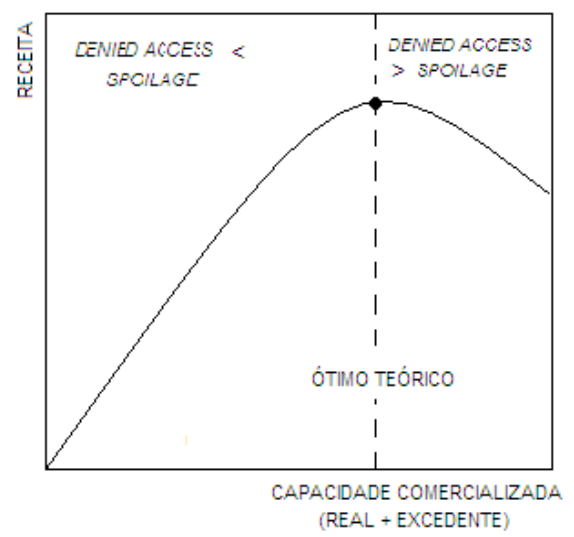

Figura 2 - Overbooking Ótimo em Relação à Receita de Overbooking.

O overbooking será lucrativo se a receita média gerada por esta prática $\left(\mathrm{R}_{\mathrm{Md}}\right)$ for maior do que o produto entre o custo associado a um embarque rejeitado $\left(\mathrm{C}_{\mathrm{DA}}\right)$ e a probabilidade de demanda pelo vôo em questão ser maior do que a capacidade oferecida $\left(\mathrm{P}_{\mathrm{DA}}\right)$, ou, em outras palavras, a probabilidade de um passageiro ser efetivamente impedido de embarcar (Daudel e Vialle, 1994). Esta condição é representada pela expressão:

$$
\mathrm{R}_{\mathrm{Md}}>\mathrm{C}_{\mathrm{DA}} \times \mathrm{P}_{\mathrm{DA}}
$$

A probabilidade $\mathrm{P}_{\mathrm{DA}}$ de passageiros terem o embarque negado é a probabilidade do número de show-up (passageiros com reserva e que comparecem ao embarque) ser maior do que a capacidade real, em número de assentos, disponível para o vôo. A condição ideal é aquela em que o número de passageiros no-show é igual ao número de passageiros show-up.

\subsection{Análise Financeira}

A fim de justificar a utilização da estratégia de overbooking pelas empresas aéreas, esta seção tem como objetivo ilustrar a potencialidade dos adicionais de receitas gerados em função dos níveis de overbooking praticados. O modelo aqui apresentado é um modelo determinístico, cuja única intenção é demonstrar, de forma simples e clara, os benefícios financeiros que a estratégia de overbooking pode proporcionar às empresas. Com auxílio do software de programação linear Lindo 6.1 foi desenvolvida a análise para um cenário de transporte aéreo hipotético.

Sendo a receita máxima obtida através do produto entre a tarifa de cada itinerário (i), para cada classe tarifária $(c)$, e a demanda pelos mesmos

$$
\mathrm{R}_{\mathrm{MÁX}}=\sum_{\mathrm{i}} \sum_{\mathrm{c}} \mathrm{TAR}_{\mathrm{i}, \mathrm{c}} \times \mathrm{PAX}_{\mathrm{i}, \mathrm{c}}
$$


e definidas as restrições associadas à capacidade ofertada (assentos disponíveis) e ao atendimento à demanda, as condições a serem satisfeitas são, respectivamente, (a) o número de passageiros aceitos não deve ser superior à oferta de assentos e (b) o número de passageiros aceitos deve ser inferior ou igual à demanda média do vôo.

Suponha uma ligação entre os Aeroportos Internacionais de Curitiba (CWB), Recife (REC) e Rio Branco (RBR): (CWB-REC e REC-RBR) que constituem três itinerários (CWB-REC, REC-RBR e CWB-RBR), dispondo de duas classes tarifárias cada um (C: executiva; Y: econômica) e com capacidade de 160 assentos no primeiro vôo e 120 assentos no segundo. Para esta condição, foram definidas as respectivas capacidades, valores relativos à demanda e tarifa do bilhete de passagem por classe tarifária, conforme mostra a Tabela 1. Assume-se, também, que o Custo de Compensação $\left(\mathrm{C}_{\mathrm{DB}}\right)$ por passageiro cujo embarque é rejeitado $(\mathrm{DB})$ é $\mathrm{C}_{\mathrm{DB}}=\mathrm{R} \$ 450$.

Tabela 1 - Valores tarifários e de demanda, por classe tarifária e itinerário para a rede de vôos.

\begin{tabular}{c|c|c|c|c} 
TRECHO & \multicolumn{2}{|c|}{ TARIFA (Reais) } & \multicolumn{2}{c}{ PASSAGEIROS } \\
& Executiva (C) & $\begin{array}{c}\text { Econômica } \\
(Y)\end{array}$ & $\begin{array}{c}\text { Econômica } \\
\text { (Y) }\end{array}$ \\
\hline CWB - REC & 1010 & 845 & 95 & 60 \\
\hline REC - RBR & 970 & 810 & 30 & 140 \\
\hline CWB - RBR & 1300 & 1080 & 45 & 90
\end{tabular}

Considerando a receita máxima $\left(\mathrm{R}_{\mathrm{MÁx}}\right)$ aquela em que a condição de denied access não se sucede e, conseqüentemente, o custo de compensação é nulo $\left(\mathrm{C}_{\mathrm{DB}}=0\right)$, a receita mínima ( $\left.\mathrm{R}_{\mathrm{Mí} N}\right)$ aquela em que todas as reservas adicionais convertem-se, obrigatoriamente, em denied boardings, e sendo $\mathrm{R}_{\mathrm{MíN}}=\mathrm{R}_{\mathrm{MÁX}}-\mathrm{C}_{\mathrm{DB}}$, os resultados obtidos pela modelagem comprovam a viabilidade, em termos financeiros, da prática de overbooking pelas empresas aéreas, quando praticado em níveis adequados.

A Figura 3 ilustra a variação de $\mathrm{R}_{\mathrm{MÁx}}$ e $\mathrm{R}_{\mathrm{MíN}}$ para os níveis de overbooking testados. Observa-se que, mesmo para a condição mais desfavorável, em que todos os passageiros com reservas confirmadas comparecem ao embarque, isto é, todas as reservas adicionais convertem-se em denied boardings, gerando custos à empresa, ainda assim é preferível utilizar a técnica de overbooking a não utilizá-la. 


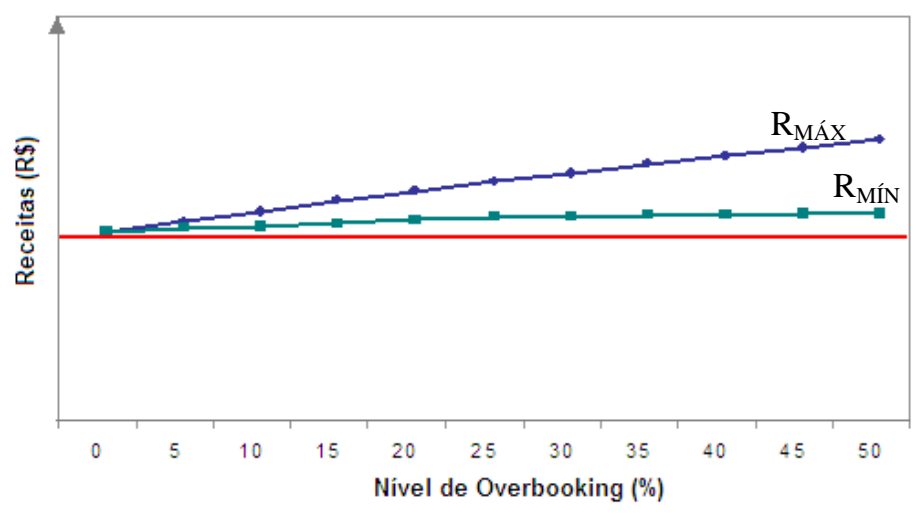

Figura 3 - Valores de $\mathrm{R}_{\text {MÁx }}$ e $\mathrm{R}_{\text {Mín }}$ por Nível de Overbooking.

As vantagens da implantação desta estratégia podem ser verificadas, também, pelos valores de Lucros Relativos. Estas variáveis representam os adicionais de receita gerados por cada nível de overbooking modelado, em relação à condição em que a estratégia não é praticada (nível de overbooking igual a 0\%). De outro ponto de vista, os Lucros Relativos representam a “perda” de receita devido à ausência da estratégia de overbooking, ou seja, a empresa abstémse de absorver a receita adicional provinda dos possíveis assentos "virtuais” comercializados. A variação da perda de receita em relação à $\mathrm{R}_{M A ́ X}$ e $\mathrm{R}_{\text {MíN }}$ está exposta na Figura 4 a seguir.

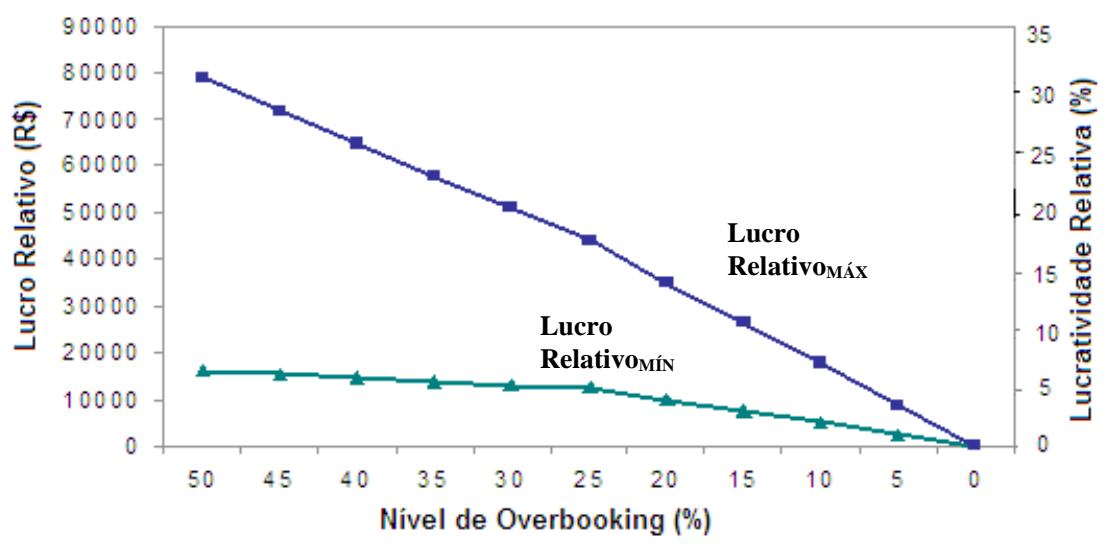

Figura 4 - Curvas de Lucro Max e Mín ( $\mathrm{C}_{\mathrm{DB}}=\mathrm{R} \$ 450$ para cada nível de overbooking).

É evidente que quanto maior o custo de compensação devido aos passageiros impedidos de embarcar, menor será o lucro obtido pela empresa em relação ao adicional de assentos comercializados. Naturalmente, dependendo das condições do mercado, podem existir níveis de overbooking cuja prática torna-se inviável financeiramente. Para ilustrar as possíveis configurações das curvas de Lucro Relativo para o cenário em questão, foram estabelecidos 
valores de $C_{D B}$ superiores ao analisado previamente $\left(C_{D B 600}=R \$ 600 / D B\right.$ e $C_{D B 700}=R \$$ 700/DB.

Analisando a Figura 5, percebe-se que o nível ótimo de overbooking é verificado para um aumento de $25 \%$ da capacidade do vôo, ou seja, a maior lucratividade relativa é atingida quando se pratica um nível de overbooking da ordem de $25 \%$, para o $\mathrm{C}_{\mathrm{DB} 600}$. Para níveis acima deste valor, o adicional de receitas proporcionadas pela venda de bilhetes tende a decrescer. Aumentando o valor de indenização $\left(\mathrm{C}_{\mathrm{DB} 700}\right)$, a curva não apresenta inclinação positiva, o que significa que, neste caso, a melhor alternativa é não aceitar reservas adicionais.

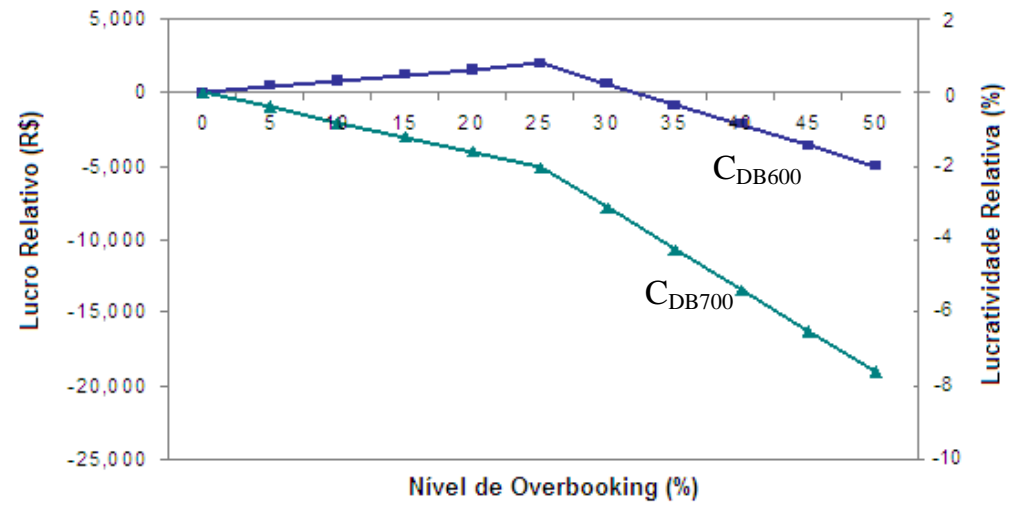

Figura 5 - Lucratividade Relativa para $\mathrm{C}_{\mathrm{DB} 600}$ e $\mathrm{C}_{\mathrm{DB} 700 .}$

Assim, pode-se constatar a veracidade da afirmação supracitada, de que para valores crescentes de custos de compensação, a lucratividade relativa decresce, podendo atingir patamares em que, a partir de então, a empresa arcará com prejuízos, quaisquer que sejam os níveis de overbooking praticados.

\subsection{Determinação do Nível Ótimo de Overbooking}

A determinação eficaz de níveis ótimos de overbooking se faz necessária a fim de minorar os impactos negativos incidentes em ambos os responsáveis pela realização do serviço de transporte (transportado e transportador) e evitar os problemas relativos a sobrevenda de assentos. Quanto menor o custo associado ao passageiro denied boarding, maior será a tolerância em relação aos níveis de overbooking praticados, resultando em um maior número de assentos adicionais comercializados (SILVA e PINTO, 2001).

Com o intuito de estabelecer políticas de reservas que permitam otimizar a receita de passageiros em cada vôo oferecido, as empresas aéreas fazem uso de modelos matemáticos de overbooking, cujo princípio básico dos algoritmos desenvolvidos é o processo de decisão em 
relação à aceitação de uma nova reserva ou se o procedimento de reservas deve ser encerrado, recusando novas reservas no sistema, baseado na maximização da receita gerada pela venda de passagens.

Pelo fato dos modelos de overbooking dependerem de previsões da probabilidade das distribuições do número de passageiros que comparecem ao embarque no momento do vôo (distribuição de chegada ao balcão do check-in), as pesquisas de overbooking estimulam, também, pesquisas relacionadas a previsões desagregadas do processo de reservas nos sistemas, de passageiros no-shows, cancelamentos e go-shows. Infelizmente, estas previsões desagregadas necessárias para os modelos de overbooking são extremamente difíceis, principalmente em decorrência dos fatores relacionados ao comportamento da demanda (MCGILL, 1999).

O principal requisito para desenvolver um modelo de overbooking é a estimação do valor de no-show esperado (COUGHLAN, 1999). Considerando as hipóteses referentes às distribuições aleatórias relacionadas ao comportamento da demanda quanto ao processo de reserva e quanto ao comparecimento ao embarque do vôo, um modelo de overbooking baseado na maximização de receita pode ser representado pela seguinte função da receita esperada:

$$
\overline{r e v}=\sum_{i=1}^{N}\left(m s_{i} \times f_{i}\right)-(\overline{d b} \times(d b \cos t+\text { wavfare }))+(\overline{b g s} \times \text { brdfare })
$$

onde $\boldsymbol{N}$ é o número de classes tarifárias $(N=1,2, \ldots, i), \boldsymbol{m s}_{\boldsymbol{i}}$ corresponde à média de passageiros show-up na classe $i ; f_{i}$ corresponde ao valor da tarifa na classe $i$; $\overline{d b}$ corresponde ao valor esperado de denied boarding; dbcost corresponde ao custo de compensação unitário; $\overline{b g s}$ corresponde ao valor esperado de passageiros go-shows embarcados; wavefare corresponde à tarifa média ponderada pelo valor de show-up e brdfare à tarifa média ponderada pelo valor de go-shows.

Os modelos de overbooking baseados na maximização de receitas requerem menos dados do que aqueles baseados na minimização de custos, os quais dependem dos custos referentes aos assentos não ocupados e dos custos associados aos passageiros rejeitados ao embarque (COUGHLAN, 1999). 
A variação estocástica dos cancelamentos de reservas e no-shows é a principal causa do mau dimensionamento dos níveis de overbooking, cujo resultado serão embarques rejeitados (ROTHSTEIN, 1971). A real possibilidade de erros neste sentido - podendo ser até mesmo “propositais ${ }^{10 ",}$ dependendo da política adotada por cada empresa - requer medidas importantes no contexto do gerenciamento de receita das empresas aéreas, como por exemplo, a análise do custo de se recusar uma reserva. Assim, em grande parte dos modelos de overbooking são atribuídos custos ao passageiro denied boarding e otimiza-se a receita menos o custo associado.

Dentre os principais fatores que aumentam a complexidade dos problemas de overbooking estão: a) a combinação de overbooking e o controle de estoque de assentos (consideração de múltiplas classes tarifárias e cancelamentos); b) passageiros cujos itinerários envolvem múltiplos vôos; c) interação com outros vôos, tanto entre os da mesma empresa como com vôos de empresas competidoras (CHATWIN, 1998).

\section{Conclusões}

O presente estudo buscou desenvolver bases para a discussão teórica e quantitativa dos impactos causados pela estratégia de overbooking em companhias aéreas. Esta estratégia faz parte de um sistema mais amplo, conhecido como Gerenciamento de Receitas (Yield ou Revenue Management), cujo objetivo principal é a otimização da receita total no mercado.

Apesar do overbooking ser uma estratégia competitiva largamente utilizada tanto por companhias aéreas quanto por prestadoras de serviços em todo o mundo - sobretudo no setor turístico, como hotelaria, aluguel de veículos, etc. -, e ser potencialmente incrementadora de bem-estar econômico, em que tanto as empresas quanto os passageiros podem ser beneficiários, no Brasil ela é pouco conhecida e, principalmente, pouco esclarecida aos usuários do transporte aéreo.

A partir da análise de viabilidade financeira realizada no estudo, pode-se dizer que não existe abuso com relação à prática de overbooking por parte das empresas aéreas, mas a gestão destas, em geral, necessita de um maior aprimoramento, com introdução de métodos mais

\footnotetext{
${ }^{10}$ Algumas empresas adotam, estrategicamente, a prática de "denied boarding premeditado", isto é, definem limites de venda acima do ideal de modo que um determinado número de passageiros tenham o embarque rejeitado.
} 
científicos para a tomada de decisão. O overbooking demanda um altíssimo rigor na análise e previsão de demanda, o que pressupõe a manutenção de um sistema de informações gerenciais, com dados detalhados das operações, muito bem estruturado. A tomada de decisão quanto ao overbooking não pode ser baseada apenas na intuição do analista de reservas e yield, mas precisa ser baseada em metodologia com forte embasamento científico, sob o risco de comprometer a imagem da empresa. Com previsões de demanda espúrias, a tendência é que os valores referentes ao número de assentos a serem comercializados acima da capacidade real disponível (e considerando a probabilidade de no-shows) certamente sejam distorcidos. Ou seja, não representarão a realidade, podendo, assim, correr maior risco de ocorrerem rejeições de embarques devido ao overbooking.

A solução para impasses desta natureza é, além da informação ao consumidor, o aprimoramento das habilidades de previsão de demanda das companhias aéreas. Assim, é essencial que sejam desenvolvidos estudos tratando dos aspectos que envolvem esta estratégia, para que o mercado de transporte aéreo possa implantar as técnicas de Gerenciamento de Receitas de forma consistente, abrangendo todos os objetos que as compõem, permitindo a otimização dos recursos e as vantagens competitivas que podem ser oferecidas por elas.

Os métodos estão disponíveis na literatura, visto que o overbooking é um tema que vem sendo estudado desde os anos 60. Portanto, é necessário agora maior investimento no aprimoramento das tomadas de decisão.

\section{Referências Bibliográficas}

BOTIMER, Theodore C. 1996. Efficiency considerations in airline pricing and yield management. Transportation Research Part A, vol. 30, no. 4 (July), pp. 307-317.

CHATWIN, R. E. 1998. Multiperiod airline overbooking with a single fare class. Operations Research, vol. 46, no. 6.

COUGHLAN, J. 1999. Airline overbooking in the multi-class case. Journal of the Operational Research Society, vol. 50, no. 11, pg. 1098-1103.

DAUDEL, S. e VIALLE, G. 1994. Yield Management, applications to air transport and other service industries. Institute du Transport Aerien ITA.

MAYO, D. 1999. Contribuições para implementação do Yield Management em empresas aéreas brasileiras. Dissertação de Mestrado, Universidade de São Paulo. São Paulo. 
McGILL, J. I. e VAN RYZIN, G.J. 1999. Revenue Management: research overview and prospects. Transportation Science, no. 2.

ROTHSTEIN, M. 1971. Airline Overbooking: the state of the art. Journal of Transport Economics and Policy, pp.96-98.

RUPPENTHAL, K. M, Toh, R. 1983. Airline deregulation and the no-show/overbooking problem. The Logistics and Transportation Review, vol. 19, no. 2.

SILVA, A. M. e PINTO. 2001. P.C.P, Gerência de receitas. Cadernos Discentes do COPPEAD, Rio de Janeiro, n. 6, p. 71-114.

Recebido em: 26/12/2005 (1 ${ }^{\mathrm{a}}$ versão) 18/08/2006 (2a versão)

Aprovado em: 18/8/2006 